\title{
CLASSIFICATION OF THE EUROPEAN UNION COUNTRIES WITH RESPECT TO THE STANDARDS OF LIVING
}

DOI: http://dx.doi.org/10.18509/GBP.2018.33

UDC: 330.59(4-672EУ)

\author{
Patryk Brambert \\ Iwona Kiniorska \\ Ewa Pałka-Lebek \\ Institute of Geography, Department of Mathematics and Natural Sciences, \\ The Jan Kochanowski University in Kielce, Poland
}

\begin{abstract}
The study evaluates the spatial differentiation in the structure of the standards of living in the European Union countries. Selected measures that represent, in an objective manner, the needs of an average resident of any EU member were analysed in detail. Those included: infant mortality, share of the pre-productive population, unemployment rate, accessibility of information and communications technologies, level of schooling, healthcare accessibility, and crime level. The basic research method used was the Ward's minimum variance procedure. In studied years, the countries with the highest standards of living included Austria, Germany, Slovenia, Denmark, Netherlands, Finland and Sweden. Conversely, the lowest standards of living were found in Bulgaria and Romania.
\end{abstract}

Keywords: standards of living, Ward's method, spatial differentiation, European Union

\section{INTRODUCTION}

Standards of living of populations are an interdisciplinary research area. Those are a matter of interest for researches representing a range of different fields. One of those is geography, which investigates both the distribution of certain phenomena in the geographical space and the interpretation of the causes of their territorial differentiation. Comprehensive understanding of this branch of science makes it justifiable for geographers to play an important role in performing analyses of the spatial structure of living standards. The issues related to living standards constitute a research area that can be both investigated theoretically and applied in practice. Those issues have attracted much discussion and become subject of considerations related to, among others, sociodemographic and economic determinants.

The research concept employed for the analysis is well suited to measure the living standards, and it also ensures the comparability of results across countries of the world, especially those of the EU. The present study makes an attempt at organizing, in an orderly manner, empirical analyses of spatial differentiation of social and economic components.

Investigations into the standards of living have been conducted within economic sciences (e.g., [1]), social sciences (e.g., [2], [3]) and geographical sciences (e.g., [4], [5], [6], [7] and [8]). Analyses of the living standards, and of their differentiation in urban and rural areas, or in different regions of Europe constitute a large group of studies (e.g., [9], [10]). The other collection of studies concerns the quality of life (e.g., [11]). 
The purpose of the present study is to classify the current $28 \mathrm{EU}$ member states depending on the living conditions of their societies. Selected measures that represent, in an objective manner, the needs of an average resident of any EU member were analysed in detail. The tool used was one of the methods of hierarchical grouping, namely the Ward's minimum variance method. The authors compared agglomeration analyses for two time series, i.e. 2011 and 2013.

For the investigations, a set of 7 variables was selected:

$\mathrm{X}_{1}$ - Infant mortality per 1,000 live births,

$\mathrm{X}_{2}$ - Percentage of population of pre-productive age, from 0 to 14 years,

$\mathrm{X}_{3}$ - Unemployment rate,

$\mathrm{X}_{4}$ - Percentage of population aged 16-74, who regularly use the Internet,

$\mathrm{X}_{5}$ - Percentage of higher education students in total population,

$\mathrm{X}_{6}$ - Distribution of population, aged 18-64 years, with respect to very good health status, $\mathrm{X}_{7}$ - Population number per a prisoner.

It should be mentioned that, in addition to substantive criteria, the selection of indexes was affected by relatively low correlation between variables (correlation coefficient lower than 0.5 ) and the availability of statistical data.

\section{RESULTS}

The grouping of the EU countries with the Ward's method resulted in constructing 2 dendrograms, separate for each year. Generally in clustering, it should be aimed to achieve a classification that is economic. That means that the number of identified subsets should not be too high, and the clusters need to be well defined and internally coherent. The analysis finally produced 2 groupings with different linkage distances, which contained 2 (linkage distance of 15) and 6 (linkage distance of 5) agglomerations.

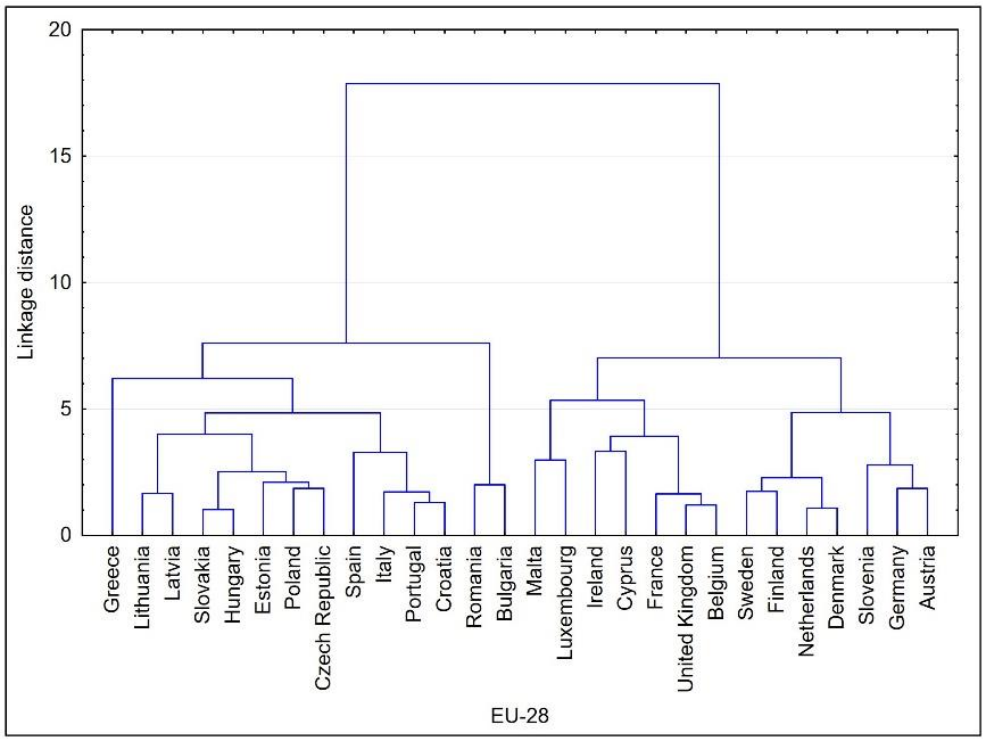

Figure 1. Agglomeration of the EU countries with respect to the standards of living, performed using the Ward's method, 2011

Source: own elaboration based on statistical data from Eurostat.

The dendrogram of the degree of similarity of the EU countries, based on parameter values in 2011, presented in Figure 1, makes it possible to determine characteristic features of those clusters. For 2011, countries were grouped into 2 agglomerations, which 
were equal in size. The first agglomeration (I) included primarily the countries of the socalled 'old' European Union, together with the 3 countries that accessed the EU in 2004 (Cyprus, Malta, Slovenia). The second cluster (II) was composed of the new member states and also included Greece, Spain, Portugal and Italy. Generally, the latter group is characterised by unfavourable demographic (especially feature $\mathrm{X}_{2}$ ) and social $\left(\mathrm{X}_{3}, \mathrm{X}_{6}\right.$, $\mathrm{X}_{7}$ ) situation, and also worse information and communications technology (ICT) infrastructure $\left(\mathrm{X}_{4}\right)$.

The comparison of agglomerations for 2011 and 2013 shows a small change, namely Malta was shifted into the second cluster. When evaluating the causes of changes proceeding at that time, it can be concluded that the highest impact on countries classification into the more numerous group was produced by negative demographic factor $\left(\mathrm{X}_{1}\right)$ and social factor $\left(\mathrm{X}_{3}\right)$.

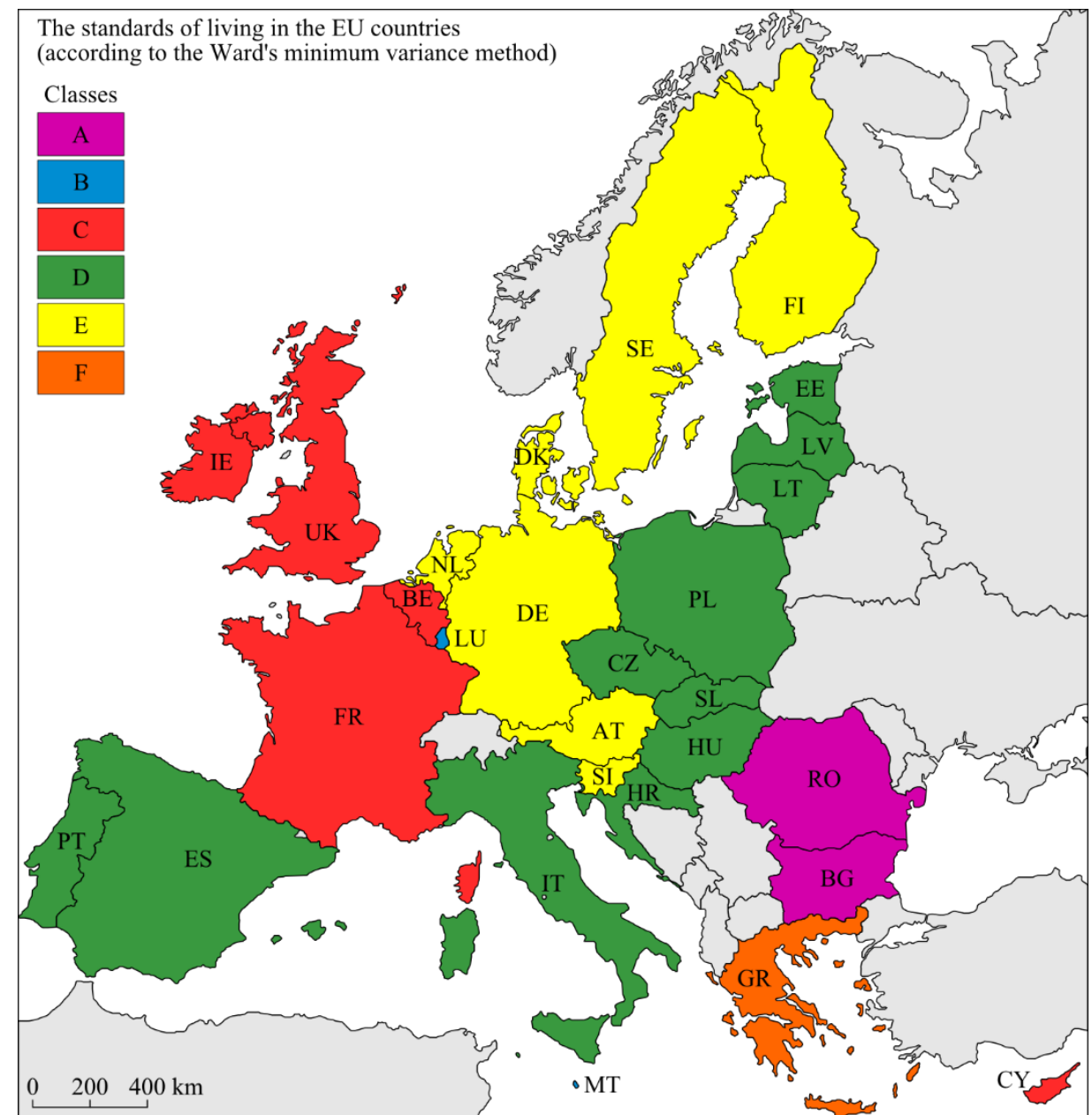

Figure 2. Spatial differentiation in the standards of living in the EU countries, obtained with Ward's minimum variance classes, 2011

Source: own elaboration based on statistical data from Eurostat.

A more detailed approach to the similarity degree analysis (objects located in close neighbourhood) with respect to living standards within 28 member states, made it necessary to produce a larger number of subsets, namely 6 agglomerations in that case. It must be remembered that at this level of clustering, agglomerations are interpreted in the sequence resulting from the shortest Euclidean distances between classified objects. 
Thus in 2011, agglomeration A is formed by Bulgaria and Romania (Figure 2). As regards the selected variables, those countries are most similar. They are characterised by the highest infant mortality $\left(\mathrm{X}_{1}\right)$, the lowest availability of ICT $\left(\mathrm{X}_{4}\right)$ and low percentage of population of pre-productive age $\left(\mathrm{X}_{2}\right)$. Additionally, Bulgaria and Romania had the lowest rating in the EU members as regards the selected parameters.

The second agglomeration (B) comprises Luxembourg and Malta, which show similarity with respect to the lowest level of schooling $\left(\mathrm{X}_{5}\right)$, and also one of the lowest unemployment rates $\left(\mathrm{X}_{3}\right)$.

A successive cluster (C) is formed by 5 countries (Belgium, Great Britain, France, Cyprus, Ireland), which show similarity in demography, revealed by a high share of population of the pre-productive age $\left(\mathrm{X}_{2}\right)$ and health condition, expressed by a high percentage of population aged 18-64, who report their health status to be very good $\left(\mathrm{X}_{6}\right)$. Agglomeration D is more numerous as it consists of 11 member states, the majority of which joined the EU at the beginning of the 21 st century. The classification into this group resulted from primarily a high unemployment rate $\left(\mathrm{X}_{3}\right)$, medium level of ICT development $\left(\mathrm{X}_{4}\right)$, low level of self-reported health status of the population $\left(\mathrm{X}_{6}\right)$, and a high crime level $\left(\mathrm{X}_{7}\right)$.

The fifth agglomeration (E) is composed of 7 countries considered to be leading in the EU (e.g., Austria, Germany, Denmark, Sweden). Those are areas characterised by advantageous demographic parameters $\left(\mathrm{X}_{1}, \mathrm{X}_{2}\right)$, the lowest unemployment rate $\left(\mathrm{X}_{3}\right)$, the highest level of ICT accessibility $\left(\mathrm{X}_{4}\right)$, and the lowest crime level $\left(\mathrm{X}_{7}\right)$.

The sensitivity of the Ward's method to extreme values, which lowers the effectiveness of grouping, is reflected in the last agglomeration $(\mathrm{F})$, containing a single element, namely Greece. This dissimilarity, however, is justified by the highest level of self-reported good health status $\left(\mathrm{X}_{6}\right)$, and, on the other hand, one of the highest unemployment rates $\left(\mathrm{X}_{3}\right)$ in the EU.

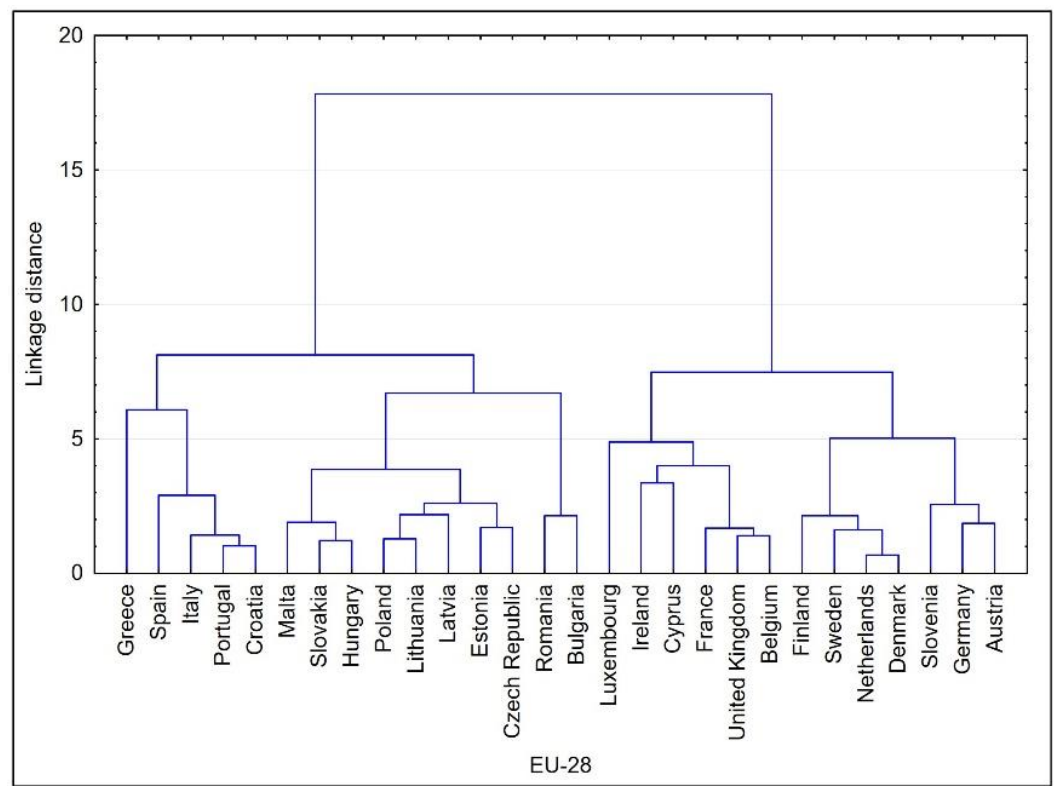

Figure 3. Agglomeration of the EU countries with respect to standards of living, performed using the Ward's method, 2013

Source: own elaboration based on statistical data from Eurostat.

The analysis of the situation of agglomerations of the EU members about the degree of homogeneity of the living standards in 2013, revealed changes in the values of the 
parameters selected for the study. Within agglomerations, shifts concerning 18 states were found. Group D, formed in 2011, was split into 2 agglomerations, namely B (Croatia, Portugal, Italy, Spain) and C (Czech Republic, Estonia, Latvia, Lithuania, Poland, Hungary, and Slovakia) - (Figure 3).

The main criteria for a country's inclusion into agglomeration B were as follows: high unemployment $\left(\mathrm{X}_{3}\right)$, low share of population of pre-productive age $\left(\mathrm{X}_{2}\right)$, and a low percentage of students in the whole population $\left(\mathrm{X}_{5}\right)$.

In group $\mathrm{C}$, on the other hand, countries showed similarities in the following variables: high unemployment $\left(\mathrm{X}_{3}\right)$, high crime rate $\left(\mathrm{X}_{7}\right)$ and a medium share of population of preproductive age $\left(\mathrm{X}_{2}\right)$.

From groups C and B, established in 2011, countries were relocated to agglomeration D, except for Malta, which was included into group C. Aggregate D comprised 6 countries altogether: Belgium, Great Britain, France, Cyprus, Ireland, and Luxembourg. Those were similar with respect to the following variables: high percentage of population of preproductive age $\left(\mathrm{X}_{2}\right)$, and higher than average availability of ICT $\left(\mathrm{X}_{4}\right)$. Figure 4 shows the spatial differentiation of the EU with respect to the standards of living in 2013, obtained with the use of the Ward's minimum variance method.

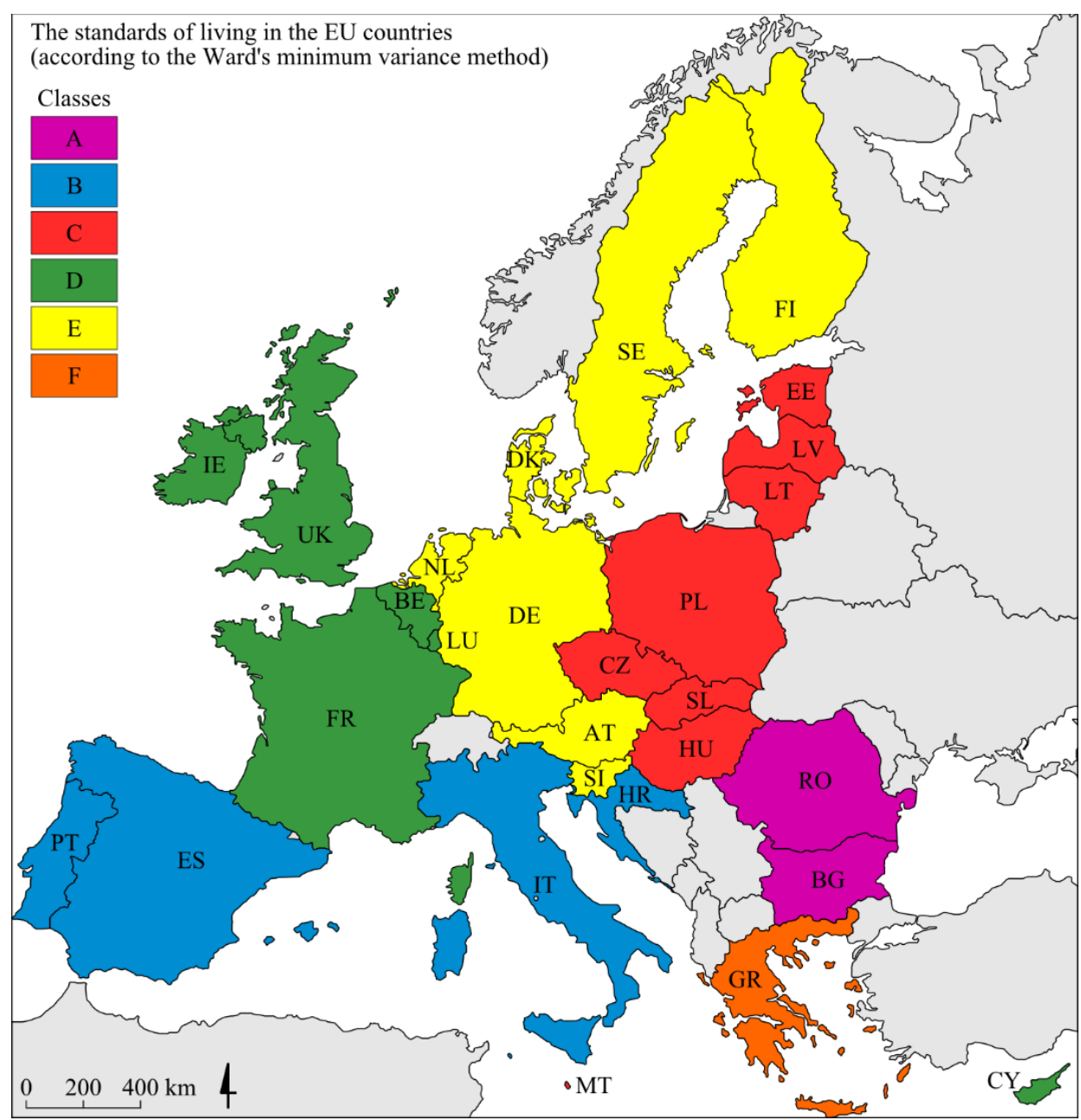

Figure 4. Spatial differentiation in the standards of living in the EU countries, obtained with the Ward's minimum variance classes, 2013

Source: own elaboration based on statistical data from Eurostat. 
Due to the similarity strength, the location of 10 countries within the 3 agglomerations did not change. As it was written, the agglomerations were arranged hierarchically from the lowest to the highest variability (variance of characteristics), i.e. A, E and F. Thus, in 2013, classification of Bulgaria and Romania into group A continued to result from the following: the highest in EU infant mortality per 1,000 live births $\left(\mathrm{X}_{1}\right)$ and the poorest supply of ICT infrastructure $\left(\mathrm{X}_{4}\right)$, and unfavourable proportion of people aged $0-14$ years $\left(\mathrm{X}_{2}\right)$. The composition of groups $\mathrm{E}$ and $\mathrm{F}$ resulted from the same set of parameters as in 2011.

As regards 2 large agglomerations (linkage distance of 15) in 2013, the first cluster (I) included groups D and E, whereas the other (II) was composed of groups A, B, C and F.

\section{CONCLUSIONS}

The living standards of a population depend on a very large number of factors. The choice of those is, to some extent, subjective, and it also determined by the availability of statistical data. Thus, the final results of investigations into living standards very much depend on the selection of diagnostic features used to describe the phenomena.

On the basis of investigations conducted for the study, a conclusion can be drawn that the living standards in the EU countries shows spatial differentiation. In accordance with the diagnostic criteria used in the study, for both years of concern, the highest standards of living were achieved in 7 EU members: Austria, Germany, Slovenia, Denmark, Netherlands, Finland, and Sweden. Conversely, the lowest living standards were observed in Bulgaria and Romania.

The EU countries, especially those in Western and Northern Europe enjoy one of the world's highest standards of living. That does not, however, hold uniformly across the whole of the EU. Sharp differences are found not only between individual states (mainly between old and new members), but also between regions within individual countries. Southern, Eastern, and South-Eastern Europe in particular, though generally regarded as belonging to the developed world, is characterised by substantially lower social and economic indexes than those that characterise Western Europe. The above statements are also confirmed by previous investigations of the authors [12].

As regards living standards, Poland is perceived to be close to the Czech Republic, Estonia, Lithuania, Latvia, Slovakia, and Hungary. Presently, only 2 countries out of 10 that accessed the EU in May 2004, i.e. Cyprus and Slovenia, may be able to achieve living standards of the states of the former 15-member EU. Other countries, including Poland, still need to provide for huge expenditure as their social and economic development requires considerable outlay.

\section{REFERENCES}

[1] Bywalec C. \& Rudnicki L. Podstawy ekonomiki konsumpcji, Wydawnictwo Akademii Ekonomicznej, Kraków, pp. 1-167, 1999.

[2] Sen A. The Standard of Living, In: G. Hawthorn (Ed.), The Tanner Lectures on Human Values, Cambridge University Press, Cambridge, pp. 1-142, 1998.

[3] Szymczak M. Przestrzenne zróżnicowanie rozwojowe warunków życia w latach 1975-1997, Przegląd Socjologiczny, Łódzkie Towarzystwo Naukowe, Łódź, vol. 49, pp. 169-198, 2000.

[4] Smith D.M. The geography of social well-being in the United States: An introduction to territorial social indicators, McGraw-Hill, New York, pp. 1-144, 1973. 
[5] Knox P. L. Level of living: a conceptual framework for monitoring regional variations in wellbeing, Regional Studies, vol. 8, pp. 11-19, 1974.

[6] Chojnicki Z. \& Czyż T. (Eds). Zróżnicowanie przestrzenne poziomu i warunków życia ludności, Biuletyn Komitetu Przestrzennego Zagospodarowania Kraju Polskiej Akademii Nauk, Warszawa, vol. 153, pp. 1-169, 1991.

[7] Pacione M. Urban environmental quality and human wellbeing - a social geographical perspective, Landscape and Urban Planning, vol. 65, pp. 19-30, 2003.

[8] Raźniak P. \& Winiarczyk-Raźniak A. Spatial distribution and differences in migration patterns and revenues of gminas in the Kraków Metropolitan Area, Bulletin of Geography. Socioeconomic Series, The Journal of Nicolaus Copernicus University, Torun, vol. 19, pp. 73-86, 2013.

[9] Sorensen J.F.L. Rural-urban differences in life satisfaction: evidence from the European Union, Regional Studies, vol. 48, pp. 1451-1466, 2014.

[10] Zuzańska-Żyśko E. Procesy metropolizacji. Teoria i praktyka, Wydawnictwo Naukowe PWN, Warszawa, pp. 1-432, 2016.

[11] Colombo E., Michelangeli A. \& Stanca L. La dolce vita: hedonic estimates of quality of life in Italian cities, Regional Studies, vol. 48, pp. 1404-1418, 2014.

[12] Kiniorska I., Pałka E. and Brambert P. Spatial differentiation within the structure of standards of living in the EU countries at the time of economic crisis, In: I. Kikerkova (Ed.), Systemic economic crisis: current issues and perspectives: research monograph, Ss. Cyril and Methodius University, Faculty of Economics, Skopje, pp. 377-388, 2013. 